\title{
Living-donor single-lobe lung transplantation for bronchiolitis obliterans in a 4-year-old boy
}

\author{
Takeshi Shiraishi, MD, ${ }^{a}$ Masafumi Hiratsuka, MD, ${ }^{\text {a }}$ Mitsuteru Munakata, MD, \\ Takao Higuchi, MD, ${ }^{\text {a }}$ Satoshi Makihata, MD, ${ }^{\text {a }}$ Yasuteru Yoshinaga, MD, ${ }^{a}$ \\ Satoshi Yamamoto, MD, ${ }^{a}$ Akinori Iwasaki, MD, ${ }^{a}$ Masanobu Yasumoto, MD,

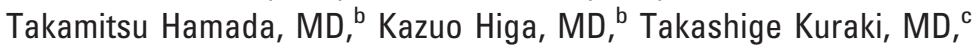 \\ Kentaro Watanabe, $\mathrm{MD}^{\mathrm{c}}{ }^{\mathrm{C}}$ Noritsugu Morishige, MD, ${ }^{\mathrm{d}}$ Tadashi Tashiro, MD, ${ }^{\mathrm{d}}$ \\ Kazuki Nabeshima, MD, ${ }^{e}$ Katsunobu Kawahara, MD, ${ }^{f}$ Kan Okabayashi, MD, ${ }^{g}$ \\ Hiroshi Yasunaga, MD, ${ }^{\mathrm{h}}$ and Takayuki Shirakusa, MD, ${ }^{\text {a }}$ Fukuoka City, Oita, \\ Koga City, and Kurume City, Japan
}

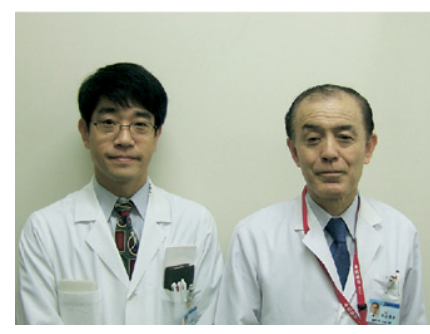

Drs Shiraishi and Shirakusa (left to right)

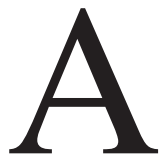

single-lobe lung transplantation from a living donor was performed in a 4-year-old boy. The transplantation was successful, and the patient recovered smoothly despite severe volume mismatch between the lung allograft and the recipient chest cavity. To our knowledge, this case represents the youngest recipient of a living-related single-lobe transplantation ever reported.

\section{Clinical Summary}

This male patient's history included diagnosis of juvenile myelomonocytic leukemia at 1 year 3 months, with subsequent peripheral blood stem cell transplantation from his mother. He later had bronchiolitis obliterans develop, and his respiratory condition progressively deteriorated thereafter. Mechanical ventilation was instituted at 4 years 10 months because of the onset of carbon dioxide narcosis. Chest computed tomography (CT) demonstrated bilateral diffuse emphysema and severe lung overexpansion.

Transplantation from a cadaveric donor is considered impossible within a limited time frame; therefore, the only realistic transplant option was considered a living-related single-lobe lung transplantation (because of the recipient's small stature). The potential donor was his mother. The heights and weights of the recipient and donor were $98 \mathrm{~cm}$ and $13 \mathrm{~kg}$ and $159 \mathrm{~cm}$ and $58 \mathrm{~kg}$, respectively.

\footnotetext{
From the Department of Surgery, Division of Thoracic Surgery, ${ }^{\text {a }}$ the Department of Anesthesiology, ${ }^{\mathrm{b}}$ the Department of Respiratory Medicine, ${ }^{\mathrm{c}}$ the Department of Cardiovascular Surgery, ${ }^{\mathrm{d}}$ and the Department of Pathology, ${ }^{\mathrm{e}}$ Fukuoka University Hospital, Fukuoka City, Japan; the Department of Surgery II, Oita University Hospital, Oita, Japan ${ }^{\mathrm{f}}$; the Department of Thoracic Surgery, National Fukuoka-Higashi Medical Center, Koga City, Japann $^{\mathrm{g}}$; and the Department of Cardiovascular Surgery, Saint Mary Hospital, Kurume City, Japan. ${ }^{\text {h }}$

Received for publication Feb 18, 2007; accepted for publication March 29, 2007.

Address for reprints: Takeshi Shiraishi, MD, Department of Surgery, Division of Thoracic Surgery, Fukuoka University Hospital, 7-5-41 Nanakuma, Jonan-ku, Fukuoka City, Fukuoka, 814-0180 Japan (E-mail: tshiraishi-ths@umin.ac.jp).

J Thorac Cardiovasc Surg 2007;134:1092-3

$0022-5223 / \$ 32.00$

Copyright $\odot 2007$ by The American Association for Thoracic Surgery doi:10.1016/j.jtcvs.2007.03.063
}

The left lower lobe was determined to be an acceptable lobe for transplantation on the basis of 3-dimensional CT volumetric evaluation of both recipient and donor, which indicated the recipient's left chest cavity to be $768 \mathrm{~mL}$ and the donor's left lower lobe to be $906 \mathrm{~mL}$. The uncertain result of this transplantation was repeatedly discussed with the recipient's family, who were willing to proceed with this plan. The Ethical Committee of Fukuoka University approved this surgery with an understanding of the experimental nature of this transplantation.

Four weeks after mechanical ventilation was started, at the age of 4 years 11 months, the patient underwent left single-lobe transplantation through a bilateral thoracosternotomy. The surgical aspects of the living-related lobar transplantation procedure have been previously described. ${ }^{1,2}$ The implantation was completed uneventfully.

Chest CT on day 1 demonstrated a well-inflated lung allograft without obvious atelectasis (Figure 1). The patient was weaned from the ventilator on day 10. A 3-dimensional CT on day 44 demonstrated the lung allograft volume to be $427 \mathrm{~mL}$, as opposed to its $906 \mathrm{~mL}$ original size before transplantation (Figure 2). This finding suggests that an oversized lung graft can work adequately, despite severe compression resulting in a graft $47 \%$ of the original size.

\section{Discussion}

In the history of living-related lung transplantation, a single donor was used in the beginning. Starnes and colleagues ${ }^{3}$ demonstrated the first successful single-lobe lung transplantation for a 12-year-

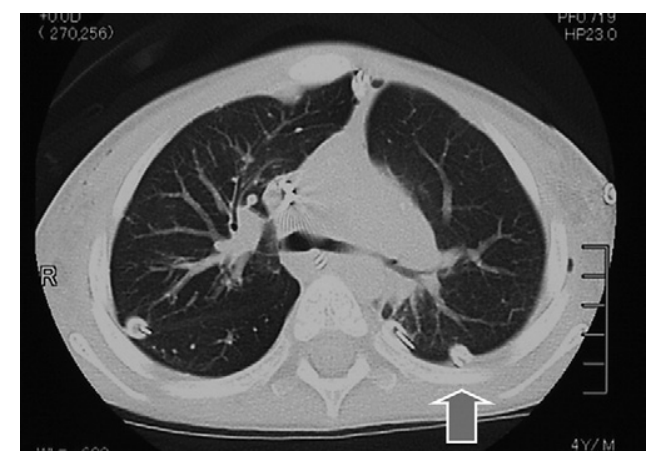

Figure 1. Chest computed tomographic scan 1 day after transplantation. Lung allograft (arrow) was well aerated, without any abnormal compression or atelectasis. 


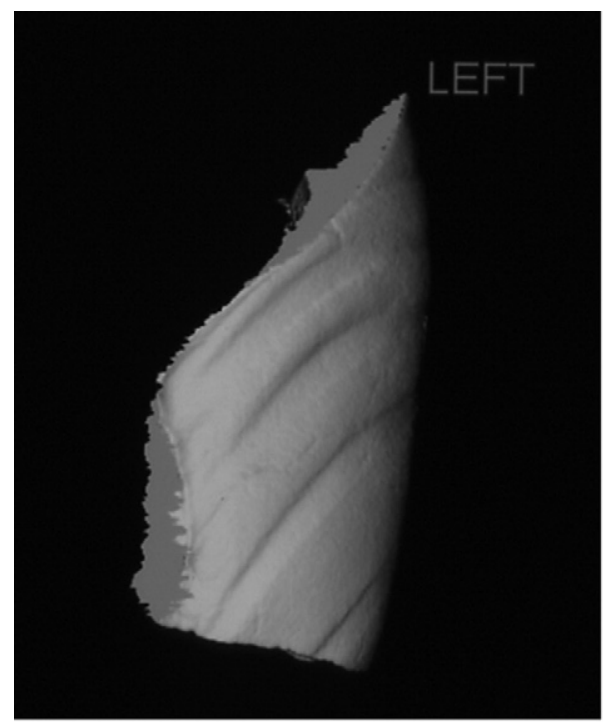

Before transplant A $\quad 906 \mathrm{ml}$

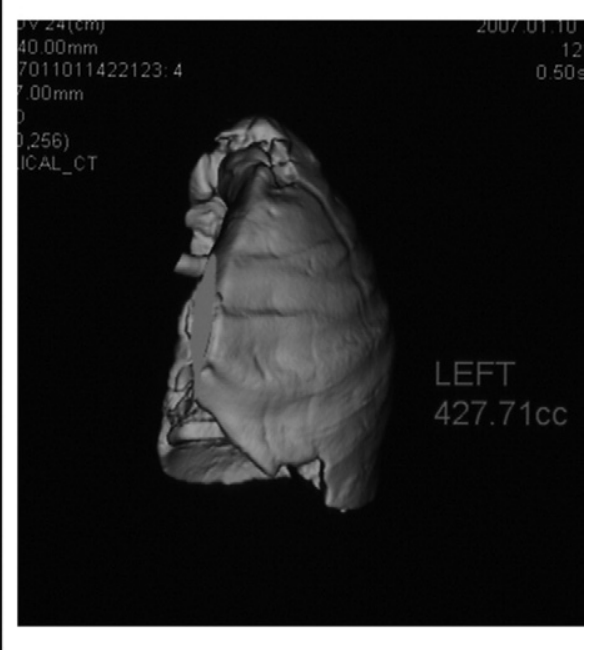

After transplant

B
Figure 2. Three-dimensional computed tomographic scans of lung allograft before (A) and 44 days after (B) transplantation. Three-dimensional computed tomographic scan in end-inspiratory point taken on day 44 after transplantation (B) showed left lung graft volume to be $427 \mathrm{~mL}$, as opposed to its $906 \mathrm{~mL}$ original size before transplantation (A). This finding suggests that oversized lung graft can work adequately despite severe compression resulting in graft only $47 \%$ of its original size. old girl. Similar successes were reported for teenaged recipients. ${ }^{3-5}$ A 4-year-old recipient with Eisenmenger syndrome, however, died immediately after transplantation of severe pulmonary edema in the allograft. ${ }^{3}$ The standard technique for this surgery is now double-lobe transplantation with right and left lower lobe grafts from two donors. Single-lobe transplantation is, however, considered when the recipient is a small child or only one donor is available.

The 3-dimensional CT showed the donor's left lower lobe to be $118 \%$ the size of the recipient's left thoracic cavity. Because the recipient's chest cavity was abnormally expanded, it was unclear whether the allograft could work. We therefore considered the possibility of a right lung volume reduction after implantation to extend the "working space" for the lung allograft if it could not ventilate. This, however, was not necessary.

Interestingly, the allograft volume gradually declined after weaning from the ventilator with the recovery of the chest wall and diaphragm toward to their original status, and the graft size finally decreased to $47 \%$ of its original. The patient recovered well, however, and his physical status continued to improve. This indicated that an overexpanded chest cavity with severe emphysematous lung may be able to accept a fairly oversized lung.

Theoretically, the recipient was "chimeric" with the lung donor because of the previous engraftment with peripheral blood stem cells. Therefore no immunosuppression might be required to control rejection, but it turned out that low-dose immunosuppression
(FK506 maintained with a trough level of $5 \mathrm{ng} / \mathrm{mL}$ and prednisolone) was necessary to control smoldering graft-versus-host disease in the liver induced by peripheral blood stem cell transplantation. No acute rejection on the allograft was found during the entire observation period. The patient recovered well and was discharged from the hospital on the 53rd day after transplantation.

We thank Drs Hiromi Wada (Department of Thoracic Surgery, Kyoto University) and Toru Bando (Department of Organ Preservation Technology, Kyoto University) for their kind donation of the lung preservation solution ET-Kyoto" used in this case.

\section{References}

1. Cohen RG, Barr ML, Schenkel FA, DeMeester TR, Wells WJ, Starnes VA. Living-related donor lobectomy for bilateral lobar transplantation in patients with cystic fibrosis. Ann Thorac Surg. 1994;57:1423-7.

2. Starnes VA, Bowdish ME, Woo MS, Barbers RG, Schenkel FA, Horn $\mathrm{MV}$, et al. A decade of living lobar lung transplantation: recipient outcomes. J Thorac Cardiovasc Surg. 2004;127:114-22.

3. Starnes VA, Barr ML, Cohen RG. Lobar transplantation. Indications, technique, and outcome. J Thorac Cardiovasc Surg. 1994;108:403-10.

4. Svendsen UG, Aggestrup S, Heilmann C, Jacobsen N, Koch C, Larsen $\mathrm{B}$, et al. Transplantation of a lobe of lung from mother to child following previous transplantation with maternal bone marrow. Eur Respir J. 1995;8:334-7.

5. Date H, Sano Y, Aoe M, Matsubara H, Kusano K, Goto K, et al. Living-donor single-lobe lung transplantation for primary pulmonary hypertension in a child. J Thorac Cardiovasc Surg. 2002;123:1211-3. 